\title{
Entrevista a Ximena Escalante
}

\section{Alfonso Varona}

Ximena Escalante nació en la ciudad de México en 1964, y estudió dirección escénica en la Universidad Nacional Autónoma de México (UNAM) en el Centro Universitario de Teatro (CUT) con Ludwik Margules. Posteriormente cursó la licenciatura en escritura y ciencias teatrales en la Real Escuela Superior de Arte Dramático (RESAD) de Madrid. De esta etapa temprana datan los textos La siesta de Pirandello (1996) y Cary Grant (1997).

Escalante irrumpió en la escena teatral mexicana con Fedra y otras griegas en el año 2002. Este texto se ha estrenado en Canadá (Ottawa, Quebec y Montreal), Nueva York, Francia (París y Lyon), Atenas y Bogotá. A partir del 2004 destacan las escenificaciones de Yo también quiero un profeta (2004), Colette (2005), La piel (2006), Andrómaca Real (2006) y Electra despierta (2009), entre otros títulos, con una sobresaliente recepción crítica del público. En sus propias palabras: "llevo una década produciendo, publicando y representando obras ininterrumpidamente -desde 2002 hasta el 2010 he tenido todos los años al menos tres obras en escena- en México y en otros países". ${ }^{1}$

La presente entrevista tomó lugar en el café El Péndulo de la colonia Roma, en la ciudad de México, el lunes 29 de julio del 2013. Buena parte de la conversación versó sobre la escenificación de sus textos más recientes, Las relaciones (sexuales) de Shakespeare (y Marlowe) y Tennessee en cuerpo y alma. ${ }^{2}$

\section{Primer acto}

¿Qué maestros/as consideras fundamentales en tu formación? ¿Cuáles consideras tus influencias literarias?

En primer lugar, mi abuelo, que era director de teatro y escritor, y que de alguna manera me empujó con la fascinación que le producía su trabajo. En segundo lugar, la biblioteca de mi casa, una biblioteca extraordinaria que me permitió desde muy joven un viaje autodidáctico, y yo misma fui reconociendo 
y encontrando. A partir de ahí tengo maestros e influencias muy precisas y directas. En el plano del teatro está Ludwik Margules, un director de teatro muy importante en México y además gran formador. Hugo Argüelles, fue mi primer maestro de dramaturgia, Antonio González Caballero, Vicente Leñero, Juan José Gurrola. Todos ellos fueron mis maestros en mi adolescencia y mi primera juventud. Me siento muy ligada a ellos en distintos sentidos, con cada uno tengo una aproximación muy directa a ciertos temas o ciertas afinidades o la elección de ciertos caminos. Ellos me indujeron a ciertos tipos de lecturas. Maestros importantes para mí son Chejov y Strindberg. Posteriormente Beckett y Jean Genet. Luego, durante el periodo que viví en España, fueron muy importantes José Luis Alonso de Santos y Ricardo Doménech. Esos han sido mis parámetros. Y desde luego mis dramaturgos griegos, Shakespeare y Pirandello.

Estilísticamente tu obra se caracteriza por el manejo de escenas breves, y de diálogos truncos entre los personajes. Temáticamente veo la reescritura tanto de la mitología (particularmente la griega), como de la vida de dramaturgos (como Colette, William Shakespeare y Tennessee Williams). Lo anterior en conjunto, con un énfasis en las relaciones amorosas. ¿Hasta qué punto estás de acuerdo con mi comentario? ¿Qué agregarias?

Estoy totalmente de acuerdo con tu comentario. Agregaría que Tennessee en cuerpo y alma no es una obra sobre el amor. Se habla sobre el amor, la demanda de amor, pero no existe una relación amorosa real. Es toda una fantasía de un personaje fantástico que está fantaseando, es una metahistoria de amor o una historia meta-amorosa. En el caso de Las relaciones de Shakespeare aunque el meollo del asunto es el amor, porque las historias que no terminó de escribir Marlowe son de amor, lo que ocurre en la historia real es más una historia de ciudad, de encuentros caóticos, de personajes. Pero no es el centro la historia del amor, aunque está ahí metido.

En tu carrera desde el estreno de Fedra y otras griegas en el año 2002, ¿cuáles textos consideras "fundamentales" en tu carrera y por qué?

Hay que entender el término fundamentales. Hay obras que a mí me gustan mucho, pero hay otras que tuvieron más importancia escénicamente y hay obras que tuvieron un éxito inesperado y que para mí no son tan importantes.

Una obra que me gusta mucho es Yo también quiero un profeta, me sigue cautivando, tanto Fedra como esa obra tienen una contemporaneidad 
importante. Se siguen representando, permanentemente Fedra es montada en algún lugar. Colette tuvo mucho éxito en su temporada, ha sido publicada tres veces, pero ahí se quedó. Otra obra que tuvo mucho éxito y ha funcionado muy bien con diversos públicos es Andrómaca Real, aunque a mí me parece una obra un poco imperfecta. Otra obra que ha funcionado extraordinariamente bien a pesar de su complejidad es Electra despierta. Una obra que tuvo muchísimo éxito en el extranjero (tuvo una gira desde Holanda hasta Italia exitosísima) fue Unos cuantos piquetitos, que es mi obra sobre Frida Kahlo, y aquí en México se presentó una vez.

Yo no podría hablar de una sola obra fundamental, pienso que todas han tenido un camino y una vida propia, todas han tenido su importancia tanto de repercusión teatral y de público como a nivel de mi propio crecimiento como autora.

¿Qué obras te han dado mayor satisfacción personal, independientemente del éxito en taquilla?

Fedra y otras griegas, Yo también quiero un profeta, Unos cuantos piquetitos, y Las relaciones de Shakespeare.

Tus textos teatrales (tanto en la publicación como en la escenificación) se han difundido en varios países. En particular, me gustaría que hablaras sobre la producción reciente de cuatro obras tuyas en Lyon, Francia, un proyecto titulado Polyptyque Escalante ¿Cómo se dio este contacto? ¿En qué consiste el proyecto? ¿Cuál fue la respuesta del público?

Es una historia bastante larga. Voy un poco para atrás: En Francia hay centros teatrales muy importantes. París tiene una repercusión teatral internacional. En Estrasburgo está la escuela de teatro más importante. En Lyon en este momento está la escuela de teatro después de Estrasburgo porque tiene la carrera de dramaturgia y la carrera de escenografía, que es una innovación. Entonces Lyon se está volviendo un escaparate teatral tan importante como Aviñón, muchas de las cosas que llegan a Aviñón pasan por Lyon, y muchas cosas que salen de Aviñón aterrizan en Lyon, y de ahí se van a París. Entonces, Lyon es en este momento un centro teatral importante. Y esta compañía de teatro funciona como un colectivo; ellos reciben a las nuevas generaciones de las escuelas de teatro, hacen una audición y hacen la compañía. Por lo tanto tienen esta compañía donde están los recién egresados, los que llevan un tiempo, y actores viejos. Mis obras, que tienen cantidad de seres humanos desde niños hasta viejos, funcionan muy bien para una compañía de este tipo. 
Hace siete años, la directora del teatro, que es además la directora artística, estaba haciendo un espectáculo de Fedras y en ese momento se acababa de publicar en París mi Fedra, con un prólogo extraordinario de Patrice Pavis, y ella la puso en su espectáculo. El espectáculo se llamaba Diez Fedras [Dix Phèdre], y cuando se montó toda la gente decía que la Fedra que más les había gustado era la mía. Eso la llevó a ella a seguir en contacto conmigo y pedirme textos constantemente. Entonces, en el 2009 se hizo la Feria Internacional del Libro en París, estaba dedicada a México y yo fui invitada como autora. Ella aceptó hacer una serie de charlas conmigo ante el público, ahí yo le di Electra y Andrómaca. Al final de esos días me dijo "voy a hacer un espectáculo con todas tus obras" y eso duró cuatro años, del 2009 al 2012. La primera obra que hizo fue El profeta, después Electra, Andrómaca y al final Fedra. Independientemente de que cada año se haya estrenado una obra, ella el segundo año tenía giras y temporadas con 2, $3 \mathrm{o}$ las 4. Es decir, las obras se estrenaron en ese teatro pero además se fueron a giras por distintos festivales en Francia, y fueron bien recibidas. Finalmente mis cuatro obras aterrizaron en el Festival de la Ciudad de México en mayo. Esto es inusitado porque no ha pasado con ningún otro autor mexicano en el extranjero. Sí ha sido una proyección importante. Algunas de estas obras se han presentado en Grecia, en Italia, en España, En Nueva York, en Los Ángeles. Sí han tenido una repercusión, especialmente las de corte griego.

Estos textos tuvieron una atracción hacia los jóvenes muy fuerte al punto que se volvieron material de lectura de la preparatoria. Yo he estado yendo a las preparatorias con los maestros de literatura, a los auditorios, para tener conversaciones sobre los mitos, Racine, y mi obra. Realmente interesantísimo.

\section{Segundo acto. Textos recientes}

Mauricio García Lozano y Jorge Ballina, respectivamente, dirigieron y escenificaron Las relaciones de Shakespeare. En el pasado has colaborado exitosamente con ellos. ¿Cuáles son en tu opinión las ventajas de trabajar con el mismo equipo en diversos proyectos?

Los tres hacemos una mancuerna teatral excepcional. Hemos hechos cosas separados, y siempre terminamos diciendo "sigamos juntos". Y no solo nosotros mismos, la gente que ve las obras nos dice lo mismo. Tenemos como una sensibilidad compartida, como que nos entendemos muy bien. Ellos sienten que han crecido conmigo, yo también he aprendido. Yo con ellos seguiré haciendo teatro hasta el fin de mis días. Pero, tampoco se trata 
de eso, no quiero que se aburran, hay otros autores y otras cosas que contar. Digamos que los he dejado que se den sus paseos por ahí, pero quiero regresar al ataque, tengo planeado hacer otras obras con ellos, por supuesto.

Ahora, Las relaciones de Shakespeare y Marlowe, es una obra muy complicada, suceden muchas cosas al mismo tiempo, hay muchas capas, es una obra que casi nadie la entiende cuando la lee. Por ejemplo, quien iba a hacer el vestuario leyó la obra varias veces y dijo "no la entiendo" y que no podía trabajar en una obra que no entendía. Cuando la fue a ver, me dijo "no es posible que no la haya entendido, si es clarísima, me encantó". Bueno, esa obra creo que ha sido entendida por Mauricio extraordinariamente bien; es una de mis obras cuyo montaje más me ha gustado cómo ha sido llevado a escena.

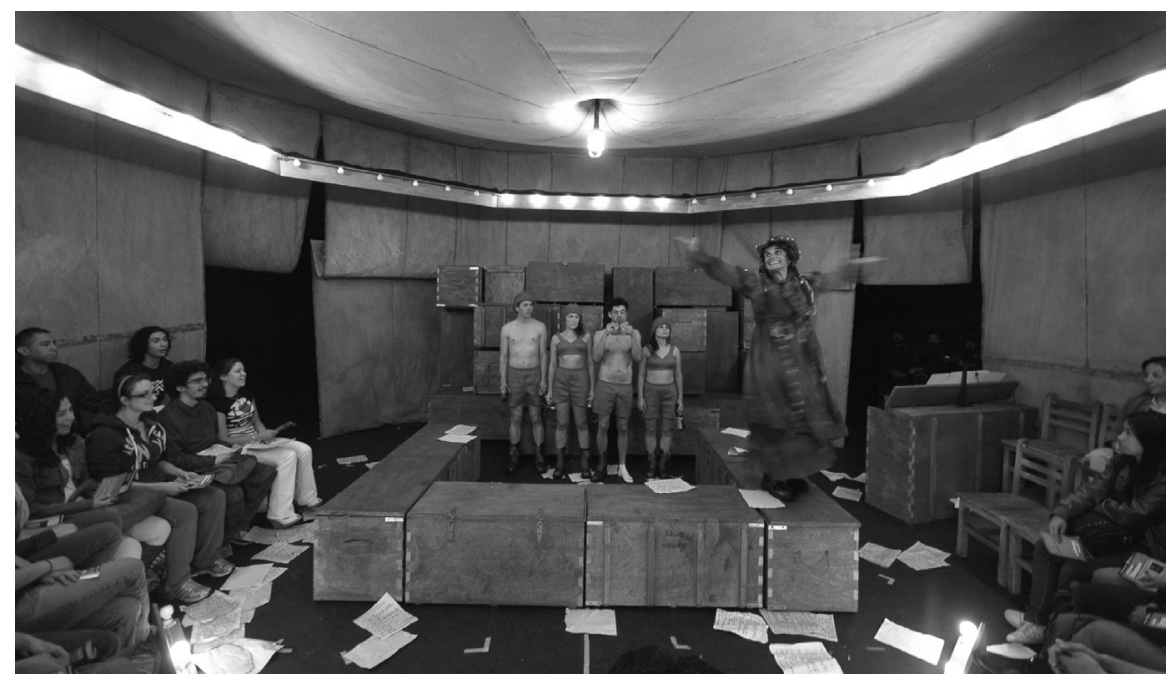

Las relaciones (sexuales) de Shakespeare (y Marlowe). Fotografía: Foro Sor Juana Inés de la Cruz.

¿Cómo surgió la idea de este texto (Las relaciones de Shakespeare)?

Yo siempre he querido reescribir las historias, y de los caminos que he tomado, sentía que me faltaba Chejov y Shakespeare. Ya había escrito una adaptación de un cuento de Chejov que se llama La mariposa, pero no sentí que había dicho el mundo chejoviano como a mí me interesaría. En cambio sí me quedé con la obsesión de hacer un Shakespeare. Leyendo la obra y estudiando me di cuenta que no solo la obra de Shakespeare es interesante, sino la vida misma de Shakespeare es apasionante, no solo su autobiografía sino el mundo en el que vivía, la teatralidad de ese momento, la historia política, social, etc. A mí me interesó hablar de ese mundo enloquecido. Un 
día tuve la claridad de lo que era la historia, me obsesioné con la amante de él. A partir de ahí surgió esta historia en la cual todo le ocurre a la amante que llega ese día y camina por las calles de Londres.

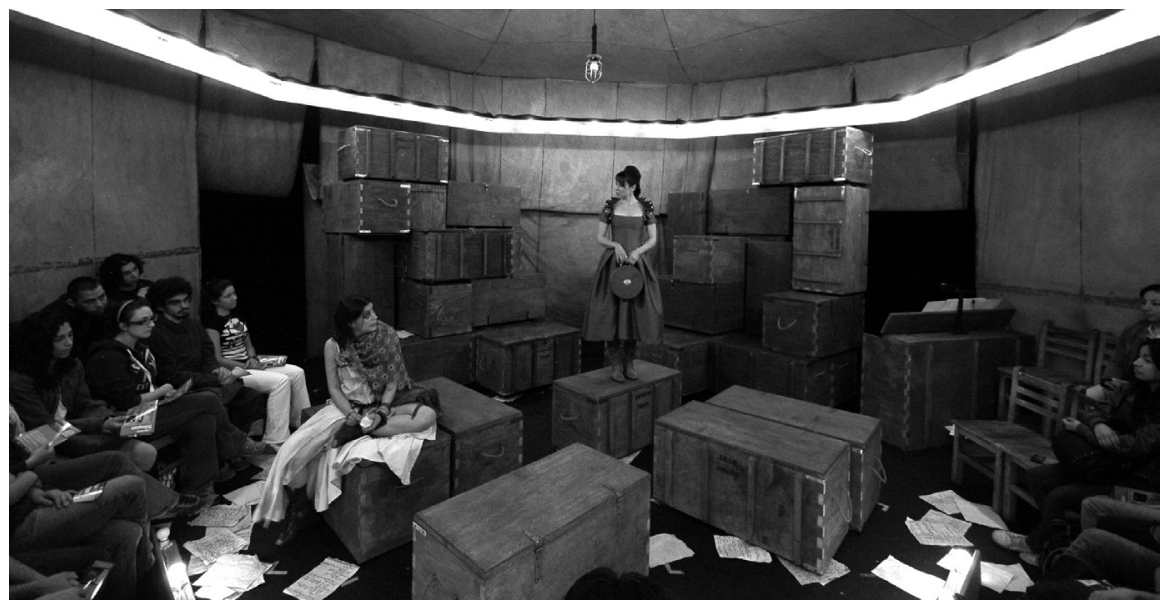

Las relaciones (sexuales) de Shakespeare (y Marlowe). Fotografía: Foro Sor Juana Inés de la Cruz.

La temática sobre Shakespeare y/o su obra es frecuente en la literatura y el cine ¿Cuál consideras tu principal influencia literaria/artística para Las relaciones de Shakespeare?

Robert Nye, quien ha escrito novelas extraordinarias alrededor de Shakespeare.

Llamó mi atención el hecho que al igual que en Colette, Las relaciones de Shakespeare ejemplifica el uso del teatro dentro del teatro; a diferencia de aquél, en este último texto los personajes de finales del siglo XVI observan obras de nuestra época. ¿Cuál es tu intención al yuxtaponer estas temporalidades?

En el texto no está marcado así. Es una decisión del director. En la obra, la amante de Shakespeare [quien tiene un manuscrito de Marlowe], no sabe leer, y la bruja tampoco sabe leer, entonces la bruja mete las escenas a un caldo, para que el caldo interprete lo que le dé la gana. Esas escenas, de hecho yo las quería hacer coreografiadas, sí quería romper con una convención de tiempo, fuera de todo momento histórico. El caldo es el universo, lo contemporáneo, lo antiguo. Quería que fuera una realidad aparte, y el director decidió que era una historia contemporánea. 
Frecuentemente veo en cartelera otros textos inspirados en Shakespeare el personaje histórico o su obra, en escenificaciones de diversas tendencias. ¿A qué atribuyes este interés en la época isabelina por parte de dramaturgos mexicanos que escriben en el siglo XXI?

Yo creo que es más Shakespeare que el mundo isabelino, el cual evidentemente se presta para cualquier tipo de ficción. Es interesante que Shakespeare sigue siendo una materia de estudio y de juego permanente. El mundo en que él vivió continúa siendo una masa de la cual se puede hacer pan infinitamente.

¿Cómo surgió la idea de tu más reciente producción, Tennessee en cuerpo y alma?

Yo tuve una crisis creativa, nunca la había tenido. Me había propuesto escribir un ciclo de tres autores; tenía claro a dos de ellos, necesitaba el tercero y no estaba segura que era él [Tennessee Williams]. Leí su autobiografía, extraordinaria. Hay una frase que dice "todos los escritores están permanentemente bloqueados", que es una frase que está en la obra. Entonces lo que quise trabajar era eso: lo que le pasa a un escritor en un proceso de bloqueo, con la necesidad de seguir escribiendo. Escribiendo la obra, fui entendiendo la naturaleza de mi personaje.

Yo hice mi tesis sobre Pirandello; en lo que coincido con él es que un personaje tiene como límite el diseño que el autor le dio. En la obra $U n$ tranvía llamado deseo, el personaje Blanche Dubois termina en un hospital psiquiátrico. Yo pensaba, “ ¿y si el personaje quiere otra cosa para sí mismo?” Esta es la historia de esa obra: cómo un autor que no sabe qué escribir, recibe la visita de un personaje diciéndole "si quieres volver a escribir, tienes que cambiar mi destino". Y de esta manera el autor recupera su inspiración.

Y a mí me salvó la obra, me sacó de una crisis creativa importante la cual doy gracias a Dios haber vivido, porque creo que sí es muy importante. Cada autor la vivirá a su modo. Para mí fue descubrir cosas de mí que yo ni idea tenía. A la obra le fue muy bien, estrenamos en octubre [2012] y la última función fue en mayo [2013], en Los Angeles, y por cierto funcionó muy bien con el público.

La Casa del Lago en el bosque de Chapultepec es el escenario ideal para esta obra. ¿Tenías en mente este espacio al momento de escribirla?

No al momento de escribirla, pero cuando quisimos hacer la obra, siempre tuve la obsesión de que no fuera en un teatro. Yo quería salir del teatro, y entonces me acordé de la Casa del Lago. En los años ochenta fue 


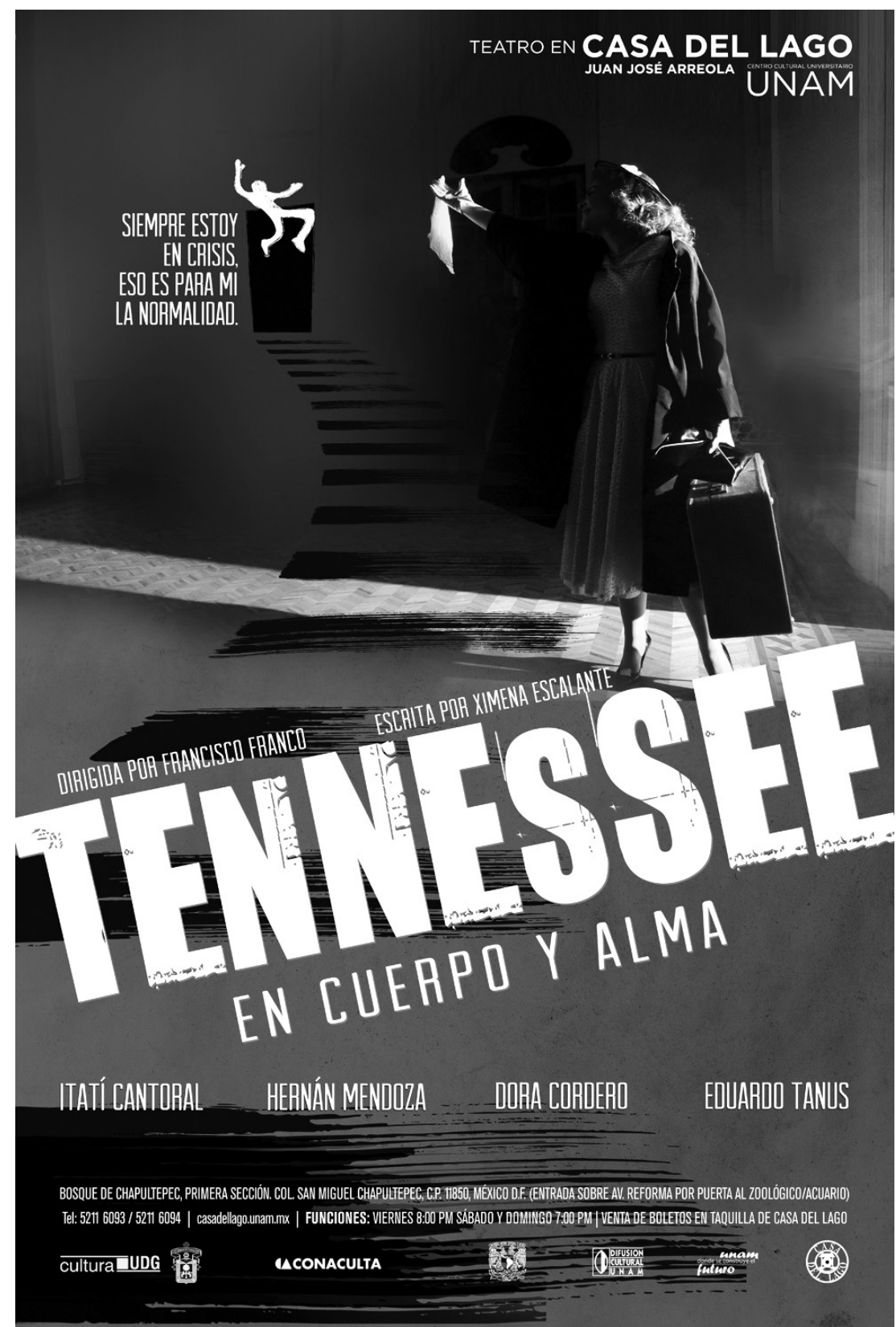

Tennessee en cuerpo y alma. Fotografía: Horacio Rico/UDG. 
muy importante. Ahí se hicieron obras de teatro que me marcaron, y llevaba décadas abandonado como centro teatral importante. Me acerqué a la dirección de este lugar; se sorprendieron que llegara un espectáculo así y me dijeron "tenemos la Casa pero no tenemos dinero". Y nosotros teníamos dinero pero necesitábamos la Casa; entonces fue la relación perfecta y funcionó increíblemente bien.

Una de las cosas que al público le gustó mucho, era regresar a la Casa del Lago, para quienes lo conocieron fue toda una revelación, llegar al bar, caminar por ahí, pasar la tarde y ver la obra. En los primeros dos meses, arrancaba la obra todavía con luz de día; la escenografía, el diseño, contemplaba esa luz, que le daba una aspecto fantasmagórico a la obra. Ya después eso se perdió, y era otra cosa, pero que también era interesante.

En este texto, la actriz Itati Cantoral, más conocida como actriz de televisión y teatro musical interpretó a Blanche Dubois. Este hecho representa una innovación con respecto a tus producciones anteriores. ¿Cuál fue el criterio a seguir?

Quería hacerlo y quiero seguir haciéndolo. Yo tengo dos opciones: Si mis "consentidos" [Mauricio y Jorge] tienen una serie de compromisos, mientras nos volvemos a encontrar yo quiero hacer las cosas completamente diferentes. Para esta segunda opción, los mecanismos tradicionales para hacer una obra de teatro a mí ya no me están funcionando.

Lo primero que hice con Tennessee fue buscar un espacio que no fuera un teatro, y por otro lado quería trabajar con otra actriz, romper un poco ese esquema de las típicas actrices de mis obras, que siempre son las mismas. Además que ella [Itatí] me buscó a mí; quería hacer una obra conmigo, y entonces yo se la di. Aceptó y se volvió productora, y ha defendido la obra contra viento y marea. Tuvimos que luchar con muchos prejuicios; la gente más prejuiciosa fue la gente de teatro. A mí se me echaron encima, más a ella, pero al final se le abrieron las puertas. Ahora está trabajando en Julio César, y de ahí está planeando hacer una tercera obra, y conmigo una cuarta, ella ahí va. ${ }^{3}$ Está demostrando que más allá de ser una estrella es una actriz, lo cual yo siempre creí.

Tennessee en cuerpo y alma se publicó este año, en una edición trilingüe (español, inglés y francés). ¿Cómo surgió la idea de este proyecto?

En un sentido Tennessee contiene estos tres idiomas: la obra está en español, Tennessee Williams es estadounidense, y Nueva Orleans tiene una influencia francesa muy importante; y por otro lado me parece una obra que 


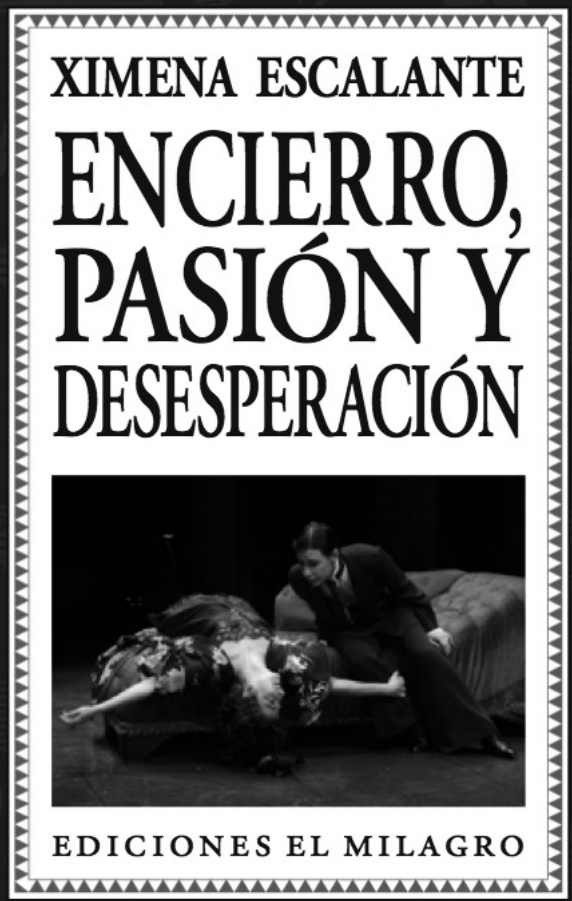

$\mathbf{T}$

$\mathbf{E}$

$\mathbf{A}$

$\mathbf{T}$

$\mathbf{R}$

$\mathbf{0}$ 
tiene el formato para funcionar muy bien tanto en Europa como en Estados Unidos. El productor de la obra, el director de la Feria Internacional del Libro en Guadalajara, me lo propuso: "hagamos una edición pero hagámosla trilingüe, porque yo quiero mover el libro por el mundo", y así fue.

\section{Tercer acto. Otras actividades, proyectos futuros}

Es sabido que escribes todos los días, no sólo teatro sino también textos de televisión, cine, narrativa y ensayo. En cada uno de estos géneros. ¿En qué trabajas en este momento?

Estoy escribiendo mi novela, con la cual llevo mucho tiempo, va a ser una novela larga. Estoy escribiendo una telenovela que sale al aire en septiembre [2013; Prohibido amar], y estoy haciendo una serie de televisión, una idea totalmente mía que me compró una televisora (tiene un título que es todavía un secreto). Estoy haciendo un libro sobre mi teoría teatral; sigo retrabajando Shakespeare, tengo comisionadas un par de obras sobre él; y en noviembre estreno la última obra que escribí, que se titula Grito. Conecta con lo que he escrito anteriormente, es sobre las relaciones entre madre e hija. Es una historia de una madre y una hija que reencarnan durante los siglos, en roles distintos. También la va a montar la compañía en Francia.

En la publicación, en septiembre [2013], en la Feria Internacional del Libro Teatral, se presenta mi libro en la editorial El Milagro con las obras sobre Colette, Tennessee Williams, y Shakespeare; con fotos, y un prólogo exhaustivo de Christopher Domínguez.

¿Qué otras actividades aparte de la escritura realizas en este momento?

Doy mi taller de dramaturgia; doy clases en la escuela de cine a guionistas, los asesoro a partir de un programa de apoyo del Instituto Mexicano de Cinematografía. También asesoro a guionistas que me han buscado a nivel personal.

Muchas gracias por la entrevista.

[Telón]

Hampden-Sydney College, Virginia 


\section{Notas}

1 "Hay una fascinación por la dramaturgia: Ximena Escalante". Sala de prensa: Libros, revistas y literatura, artes escénicas 19 Nov 2010. Conaculta. Web 26 Mayo 2012. <http://www.conaculta.gob. $\mathrm{mx} /$ sala prensa_detalle.php?id=9582>

2 Las relaciones de Shakespeare: en cartelera del 19 de abril al primero de julio del 2012 , Foro Sor Juana Inés de la Cruz. Tennessee en cuerpo y alma: en cartelera del 20 de octubre 2012 al 10 de febrero del 2013, La Casa del Lago Juan José Arreola.

3 En cartelera del 30 de mayo al 28 de julio del 2013 en el teatro Julio Castillo. Dirigida por Claudia Ríos. 